\title{
Effects of dietary weight loss on obstructive sleep apnea
}

\author{
Imran H. Iftikhar
}

Received: 26 April 2013 / Accepted: 19 July 2013 /Published online: 4 August 2013

(C) Springer-Verlag Berlin Heidelberg 2013

To the Editor:

The validity of the results of the meta-analysis by Dr. Anandam and colleagues [1] regarding the effects of dietary weight loss on obstructive sleep apnea is suspect because of the following reasons:

1. The data extraction on apnea-hypopnea index (AHI) from the studies included in this meta-analysis seems to have a selection bias. The authors included the study by Schwartz et al. [2] which only reported the NREM AHI, and no REM AHI was reported for their 13 study participants. Similarly, the study by Smith et al. [3] reported separate AHI data for NREM and REM sleep. However, the authors of this meta-analysis selectively included the NREM AHI data and left out the REM AHI data.

2. There also appears to be a contamination bias in the baseline characteristics of the study populations of included studies. Two of their included studies $[4,5]$ included study participants that were concurrently on continuous positive airway pressure (CPAP). In the study by Foster et al. [4], at least $5 \%$ of the included participants were on CPAP. Similarly, in the study by Nerfeldt et al. [5], of the 33 study participants who started the study, 19 were on CPAP. Although in both studies polysomnographic assessments of AHI were performed without the CPAP, the study population of these two studies does not match with the rest of the included studies in this meta-analysis in which the sole intervention was dietary weight loss.

3. In their analysis of the pre- to postintervention on body mass index and AHI, it is unclear why the authors chose to use the Mantel-Haenszel method of meta-analysis. This method is used for the meta-analysis of dichotomous outcomes, and generally, an inverse-variance method is

I. H. Iftikhar $(\bowtie)$

Columbia, SC, USA

e-mail: imran.iftikhar@uscmed.sc.edu used for the continuous variables. This is an incorrect way of analyzing paired data of means and standard deviations (SD).

4. There is a major statistical error in analyzing the AHI data from the study by Foster et al. [4] in Fig. 4. For the difference in AHI between control and intervention, the authors used a mean AHI of -5.4 and SD of 1.5 for the intervention group and a mean AHI of 4.2 and SD of 1.4 for the control group. Whereas, Foster and colleagues clearly stated that 1.5 and 1.4 were actually the standard errors and not SD. It is incorrect to combine SDs with standard errors in a meta-analysis.

5. Similarly, in Figure 4, it is not clear as to how the authors calculated the SD of difference for the difference in AHI between control and intervention groups for the study by Smith et al [3].

\section{References}

1. Anandam A, Akinnusi M, Kufel T, Porhomayon J, El-Solh AA (2013) Effects of dietary weight loss on obstructive sleep apnea: a metaanalysis. Sleep Breath 17(1):227-234

2. Schwartz AR, Gold AR, Schubert N, Stryzak A, Wise RA, Permutt S, Smith PL (1991) Effect of weight loss on upper airway collapsibility in obstructive sleep apnea. Am Rev Respir Dis 144:494-498

3. Smith PL, Gold AR, Meyers DA, Haponik EF, Bleecker ER (1985) Weight loss in mildly to moderately obese patients with obstructive sleep apnea. Ann Intern Med 103:850-855

4. Foster GD, Borradaile KE, Sanders MH, Millman R, Zammit G, Newman AB, Wadden TA, Kelley D, Wing RR, Pi-Sunyer FX, Reboussin D, Kuna ST, Sleep AHEAD Research Group of Look AHEAD Research Group (2009) A randomized study on the effect of weight loss on obstructive sleep apnea among obese patients with type 2 diabetes: the Sleep AHEAD study. Arch Intern Med 169(17):1619-1626

5. Nerfeldt P, Nilsson BY, Mayor L, Udden J, Friberg D (2010) A twoyear weight reduction program in obese sleep apnea patients. J Clin Sleep Med 6(5):479-486 